CZU:811.111'373.7

https://doi.org/10.52505/1857-4300.2021.1(313).10

ORCID: 0000-0003-3128-5697

\section{Felicia BANU}

Universitatea Pedagogică de Stat „Ion Creangă” din Chişinău
PARTICULARITĂȚI SEMANTICE

ALE UNITĂȚILOR FRAZEOLOGICE

CU COMPONENTE ZOONIME ÎN LIMBA ENGLEZĂ

\title{
SeMANTIC PECUliarities OF PHRASEOLOGICAL UNITS WITH ZOONYM COMPONENTS IN THE ENGLISH LANGUAGE
}

\begin{abstract}
Every nation has its own worldview reflected in the language which depends on customs and traditions, on the occupation and the lifestyle of the nation, which keeps ethno-cultural information and expresses specific ethnic mentality. The problem of interaction between language and culture is of interest to many scientists nowadays. One of the ways to study a culture is to analyze its phraseological units. For centuries phraseological units have been keeping track of folk wisdom, which was passed from generation to generation, so they carry culturally important information. Zoonyms as components of phraseological units that realize a series of connotative semes, depending on various associations connected with animals. Connotation is based on social, regional, cultural and other factors, as well as emotionally conditioned factors. The purpose of the article is to determine the semantic features of phraseological units with zoonym component as well as to identify the universal and national characteristics of phraseological units in the English language.
\end{abstract}

Keywords: phraseological unit, phraseologism, zoonym component, phraseological meaning, semantics, typology, popular terminology.

Rezumat. Fiecare națiune are propria sa viziune asupra lumii reflectată în limba care este marcată de obiceiuri și tradiții, de ocupații și stilul de viață. Prin structurile sale semantice, limba păstrează informații etno-culturale și exprimă mentalitatea etnică specifică poporului. Problema interacțiunii dintre limbă și cultură este de interes major pentru oamenii de ştiinţă din zilele noastre. Una dintre modalităţile de studiere a culturii este limba, inclusiv analiza unităților sale frazeologice. Timp de secole, unitătile frazeologice păstrează date din lumea materială şi spirituală, reguli ale înțelepciunii populare transmise din generație în generație. Așadar, limba poartă importante informații culturale. Zoonimele, în calitate de componente de bază ale unităților frazeologice, comportă o serie de semne conotative în funcție de diversele asociații legate de animale. Conotaţia se bazează pe factori sociali, regionali, culturali, precum și pe factori condiționați emoțional. Scopul articolului este de a determina trăsăturile semantice de bază ale unităților frazeologice cu 


\section{PfDillologia}

componente zoonime, precum și de a identifica caracteristicile universale și naționale ale componentelor frazeologismelor limbii engleze.

Cuvinte-cheie: unitate frazeologică, frazeologism, zoonim, sens frazeologic, semantică, tipologie, terminologie populară.

Limba este principalul mijloc de exprimare a spiritualității umane la nivelul căreia se păstrează, ca într-un tezaur, atât specificul, cât și toate modificările intervenite în mentalitatea unui popor de-a lungul timpului. Împărtășim ideea cercetătorului român Th. Hristea, potrivit căreia „... adevărata bogăție a unei limbi este dată, în mare măsură, și de bogăția ei frazeologică”, iar „după „tezaurul lexical”, cel „frazeologic” ne permite să clasăm o limbă printre idiomurile sărace, bogate sau foarte bogate" (1984, p. 134). Frazeologia, ramură relativ nouă a științei, deschide mereu noi direcții de cercetare. Una dintre direcțiile prioritare de cercetare ale frazeologiei secolelor XX-XXI este studiul fondului frazeologic din perspectiva identificării imaginilor universale și specifice în diverse limbi. Din această perspectivă, în cele ce urmează, vom examina unităţi frazeologice cu componente zoonime în limba engleză.

Vocabularul zoonimic merită o atenție specială și pentru că, respectând normele limbajului, el formează un subsistem specific cu propriile legi. Este știut că limba fixează doar acele expresii figurate care sunt asociate cu standardele culturale și stereotipurile naționale ale poporului și care, atunci când sunt utilizate în vorbire, reproduc mentalitatea caracteristică unei anumite comunităti lingvistice.

În calitate de elemente ale terminologiei populare, zoonimele au un statut specific în virtutea faptului că ele au funcționat de-a lungul veacurilor în cadrul sistemului limbii. Ele au fost investigate de către filosofi, logicieni, antropologi, psihologi și, doar în mod sporadic, de către lingviști. Animalele apropiate de viața și activitatea omului influențează asupra formării concepțiilor estetice ale societății, constituind componente indisolubile ale culturii comunității lingvistice. Omul, el însuși un animal, dar un animal social, are, conform filozofilor antici, o existență comună cu celelalte animale, care 1-au fascinat mereu, i-au trezit interesul de a efectua observații asupra lor, evocându-le în reprezentările lor despre lume (mituri, legende, povești, proverbe) și atribuindu-le valori simbolice. Dintre toate ființele vii, doar animalele posedă deprinderi specifice, având un tip de comportament și un stil de viață individual, la fel ca și ființele umane. De aceea cuvintele care denumesc animale sunt utilizate pe larg pentru a descrie lumea interioară a omului și particularitățile comportamentului său. În limba engleză, zoonimele sunt o clasă nominală puțin studiată din punctul de vedere al procedeelor de formare (lingvistice, lexicale), precum şi al semnificaţiei acestora. Grupul lexico-semantic al numelor de animale este cel mai important segment care exprimă viziunea și mentalitatea națională. Cercetătoarea rusă V. Telia menționează că numele animalelor, ca unități nominative ale limbii ,direct sau indirect, prin conotațiile lor culturale, sunt conectate la cultura spirituală și materială a oamenilor" (1998, p. 131). 
Studierea unităților frazeologice cu componente zoonime permite evidențierea particularităților culturale ale oricărui popor. Menționăm că numele animalelor în diverse limbi conțin calităţi și caracteristici diferite, determină asocieri diferite. Cercetătoarele A. A. Kiprijanova (2001, p. 69) și I. V. Kurajova (2007, p. 110) consideră că acest fapt atestă ,,individualitatea gândirii figurative a unui popor și este un proces asociativ-psihologic complex care arată de asemenea și diferențele existente între diverse grupuri etnice privitoare la tabloul valoric al lumii. Din acest punct de vedere, zoonimele acționează, pe de o parte, ca elemente ale unei culturi, iar pe de altă parte, ca elemente ale unei limbi. Deci, ele pot face obiectul unei cercetări lingvo-culturologice.

Natura duală a zoonimelor ca semne ale unei limbi este evidentă pentru o persoană care cunoaște limba şi valorile culturale naţionale, întrucât semnele de limbă pe care le folosește vorbitorul reflectă, în același timp, și conţinutul valoric cultural (constituit în semnificaţie). Prin urmare, în zoonime sunt codificate, într-un mod anume, semnificațiile culturale ale unei comunități lingvistice. Aceasta este o manifestare a specificului percepţiei umane a realităţii pe care vorbitorii unei limbi l-au fixat în tabloul lingvistic despre lume încă din cele mai vechi timpuri. Astfel, zoonimele (ca elemente ale culturii unui popor) servesc drept unul dintre instrumentele principale în reprezentarea specificului cultural național.

Însă ca varietate a lexicului expresiv, zoonimele sunt folosite pentru a evidenția calitățile pozitive sau negative ale unei persoane, prin compararea persoanei cu animalul. Or, rolul animalelor în viața umană întotdeauna a fost extrem de mare, mai ales la începutul dezvoltării civilizației, când oamenii și animalele au coexistat în vecinătatea naturală. În folclorul oricărui popor, dar și în primele surse scrise (în cazul în care acestea sunt reprezentate), eroii sunt comparați metaforic cu diferite animale. Numele animalelor adesea sunt asociate cu simbolismul popular și mitic. Probabil, acest lucru datează din momentul în care triburile se închinau la imaginile $\mathrm{cu}$ animale totemice. Ulterior, unele dintre animalele au devenit întruchiparea calităților pozitive sau negative (mai des - negative) pe care le posedă o persoană, de exemplu: turkey $($ curcan) = „om prost, înfumurat”; viper (viperă) = „om rău”; wolf $($ lup $)=$,om lacom, crud, rău”.

Cercetătorii care s-au preocupat de studiul frazeologiei engleze au propus o serie de clasificări ale unităţilor frazeologice, bazate pe principii diferite. Spre exemplu, la baza clasificării efectuate de Logan Smith au fost puse principiile tematice și etimologice. Indicând sursele de origine ale anumitor unități frazeologice engleze și grupându-le după acest criteriu, autorul a elaborat clasificarea tematicăetimologică (1995, p. 65). Lingvistul american consideră că frazeologismele cu componente zoonime pot fi împărțite în următoarele grupuri:

1) bovinele (vitele cornute mari): to take the bull by the horns - a lua taurul de coarne „, a acționa hotărât, prompt”; a bull in a china shop ,a acționa neîndemânatic"; to put the cart before the horse - a pune carul inaintea boilorl a pune căruța înaintea cailor ,a face totul invers, anapoda";

2) felinele/ pisica: to bell the cat „a lua inițiativa într-o afacere periculoasă”; a cat may look at a king - uită-te, nu este interzis; 
3) ovinele/ oaia: a black sheep - oaie neagră, se spune despre o persoana care se deosebește de ceilalți membri ai unui grup social printr-o conduită necuviincioasă; to make sheep's eyes at smb. - lit. a face ochi de oaie ,, a se uita (la cineva), a privi (pe cineva) cu ochi îndrăgostiți”;

4) porcinele/ porcul: to pig together - a face porcării ,a trăi ca porcul, în locuință murdară"; to buy a pig in a poke, se spune despre un lucru pe care nu-1 cunoști până nu intri în posesia lui;

5) păsări: fine feathers toke fine birds - păsările frumoase sunt frumoase prin penajul lor „haina îl înfrumusețează pe om”; when the sky falls we shall all catch barks - a visa cai verzi pe pereți; one swallow does not make a summer o rândunică nu face primăvara;

6) păsări domestice: to be no chicken - nu mai fi pui! (/ copil!) ,,a ieși din vârsta copilăriei"; an ugly duckling - rățuşca cea urâtă;

7) insecte: to fly on the wheel-musca la arat, se spune despre o persoană care își exagerează foarte mult semnificația/ rolul, importanța; a close mouth catches de flies - în gura închisă, musca nu va intra (Cine tace, nu păcătuiește).

Potrivit cercetătorului Logan Smith (ibidem, p. 53), unitățile frazeologice cu componente zoonime care reprezintă imagini de șerpi, viermi și insecte sunt, în mare parte, proverbe vechi sau împrumuturi din limba franceză.

Unele frazeologisme engleze includ imagini ale două animale simultan: to lead a cat-and-dog life - a se impăca precum pisica cu câinele (este folosit contrastul dintre pisică și câine pe baza antagonismului lor constant); all his geese are swans - toate gâștele îi sunt lebede, „este mai bine (se spune despre un om care exagerează totul, despre un lăudăros)".

Potrivit cercetătorilor S. Granger și F. Meunier, în sistemul frazeologic al limbii engleze este destul de răspândită utilizarea a două zoonime aflate în relații de antonimie/ contrast (2008, p. 231), spre ex.: neither peacock nor sparrow nici păun, nici vrabie (nici câine, nici ogar, nici cal nici măgar, ,nici păuniță, nici cioara"). Frazeologismul are imaginea construită pe contrastul dintre penajului bogat al păunului şi penajul modest al vrabiei, simbolizează contrastul, diferența profundă dintre cele două grupuri de oameni (în raport cu care a fost utilizat) și denotă o persoană care a părăsit deja un grup, dar nu a aderat încă la altul. Aici ar fi de menţionat faptul că ornitonime sunt cel mai des utilizate pentru a exprima poziția socială a unei persoane.

Logan Smith clasifică frazeologismele potrivit componentei lor principale în categorii, dintre care relevante pentru noi sint: zoonimele: It is a silly fish, that is caught twice with the same bait - prost este peștele care se prinde cu aceeași momeală de două ori; somatisme: to have a head on one shoulders a avea cap pe umere ,a fi lucid, a fi realist”; to knit one 's brows-a-şi incrunta sprâncenele - „a privi cu asprime”; to nose into - a-şi băga nasul unde nu-i fierbe oala; a umbla cu râtul, ,a se amesteca, a interveni acolo unde nu are ce căuta, în probleme care nu-1 privesc".

Frazeologul american nu doar descrie semantica frazeologismelor analizate, ci dezvăluie și etimologia multora dintre ele, le stabilește originea, precum şi 
componenta motivaţ̧ională ce s-a aflat la baza apariţiei unității frazeologice. Astfel, apariţia unităţii frazeologice to lead a cat-and-dog life ,a se înțelege ca pisica cu câinele" este motivată de duşmănia tradiţională dintre aceste animale. În opinia lui Logan Smith, unitățile frazeologice în care figurează zoonimul wolf, spre ex.: to throw to the wolves - lit. a-l da lupilor ,a lăsa (pe cineva, ceva) în voia sorții, la nimereală"; to take the wolf by the ears - a nimeri într-o capcană - în mare parte sunt împrumutate din alte limbi, adesea din limba franceză (1995, p. 55).

Datorită coincidenței cartografierii mentale a realității la purtători de limbi diferite, la diverse popoare apar elemente comune ale culturii, aşa-numitele universalii culturale. În limba engleză există un număr destul de mare de unități frazeologice cu componente zoonime ce au echivalente totale sau parțiale în alte limbi.

Imaginea-simbol de identificare a animalului a fost influențată de diferite concepte. Ar putea exista două sau chiar mai multe opinii despre un anumit animal. După părerea noastră, un interes special îl reprezintă zoonimele care pot caracteriza o persoană atât din punct de vedere pozitiv, cât și negativ. Analiza unităților frazeologice examinate conduce la concluzia că în limba engleză există numeroase zoonime care descriu persoana fie din punct de vedere pozitiv, fie negativ, având o dubla conotație evaluativă. Următoarele zoonime reflectă trăsături pozitive ale omului: Lamb (mielul): as innocent as a lamb - nevinovat ca un miel(ușel); Dove (porumbelul): as harmless as a dove - nevinovat ca un porumbel; Hawk (șoimul): as watchful as a hawk - vigilent ca un șoim ș.a. Trăsăturile negative ale omului sunt reflectate de următoarele zoonime: Pig, hog (porc): behave like a hog - a se comporta ca un porc; as fat as a pig-gras ca un porc; Snake (șarpe): be lower than a snake's belly ,josnic”; Wolf(lup): as greedy as a wolf-lacom ca un lup; Monkey (maimuță): as tricky as a monkey - șireată ca o maimuță.

E de observat că în structura frazeologismelor mai frecvent se regăsesc zoonimele: cat, dog, horse, bird, goose, fox, swan, deer, hare, peacock. Aceste zoonime reflectă atât trăsăturile de caracter pozitive, cât și negative ale unei persoane. De exemplu: as fat as a pig-gras ca un porc; as strong as a bull - puternic ca un taur; as fleet as a deer-iute, rapid ca o căprioară; as timid as a hare - fricos ca un iepure; as gaudy as a peacock - ingâmfat ca un păun; as silly as a goose - prost ca o gâscă; as graceful as a swangrațioasă ca o lebădă; as cunning as a fox-vicleană ca o vulpe; as fast as a hare - iute ca un iepure; hastily bat killing of fleas - agil ca un purice etc. Prin urmare, utilizarea corectă şi atentă a acestora în comunicare este un lucru foarte important.

Acum vom analiza câteva frazeologisme cu componenta zoonim în care acelaşi animal desemnat posedă caracteristici contradictorii, fapt frecvent în frazeologia engleză. Cel mai vechi animal domestic în aproape toate culturile este 


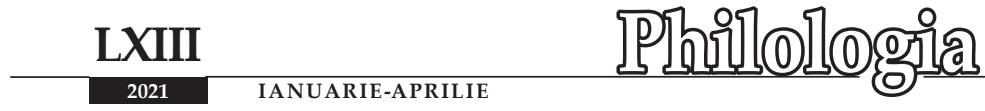

câinele, motiv pentru care comparaţia cu câinele se întâlneşte cel mai des în acest grup lexico-semantic de frazeologisme. Conotaţiile negative ne sugerează idei despre câine ca fiind o creatură oropsită, uneori trăind în cele mai grele condiții, dependent de stăpân, destinat protecției locuințelor, vânătorii etc. lead a dog's life - a duce o viața de câine ,a suferi, a se chinui”; treat like a dog - a fi tratat ca un câine ,a fi necăjit, batjocorit de oricine”; dressed up like a dog's dinner îmbrăcat ca o paparudă ,îmbrăcat vulgar” etc. În același timp, caracteristici ale câinilor ca fiind loiali, prietenoși, rezistenţi au stat la baza formării unui şir de frazeologisme cu conotaţii pozitive: die for one dog - credincios ca un câine, credincios până la moarte (or, câinele rămâne loial stăpânului său până la sfârșitul vieții); funny dog - tip amuzant.

Analizând trăsăturile semantice ale zoonimului cat (pisică) constatăm că animalul desemnat cu acest nume este considerat prieten al omului. Pisica a câștigat încrederea și dragostea omului datorită blândeței, inteligenței și prudenței sale: as tame as a cat is quite tame - blândă ca o pisica; as wary as a cat „foarte atentă”. Fiind animale sălbatice, pisicile mai sunt și viclene, înșelătoare - trăsături negative ce-au pătruns şi în frazeologie: cat in the pan „trădător/ trădătoare”; cat shuts its eyes when stealing cream to close their eyes to their sins - a inchide ochii asupra propriilor greşeli.

Zoonimul horse (cal) are conotații pozitive care decurg din rolul lui în viaţa omului, ca ființă rezistentă, cf.: strong as a horse, strong as an willing horse sănătos ca un call puternic ca un cal, harnic ca un call docil/ muncitor; alături de care, aducem şi un frazeologism cu conotaţie negativă: ride the fore horse is to be in front - a sări peste cal; a dark horse - oaie neagră.

În cultura britanică omul este adesea caracterizat şi prin activitatea sa profesională. În limba engleză există unităţi frazeologice cu componente zoonime din jargonul profesional, însă care se referă la activitățile politice și de afaceri ale omului, de exemplu: bull ,speculant care influenţează majorarea/ creşterea taxelor”; bear ,agent de bursă care influenţează reducerea prețurilor”; deer „speculator de valori mobiliare”, duck, ,politician al cărui mandat se încheie şi va părăsi fără onoruri politica”, a fat cat ,persoană bogată, privilegiată de soartă”.

O altă concepție deosebită despre lume fixată în frazeologismele cu componentă zoonim se manifestă sub forma etichetării figurilor istorice, precum cele atestate la Shakespeare: the Hog was Richard III; the Lion Heart Richard the lion Heart („Richard Inimă-de-Leu”), the Swan of Avon („Lebăda de pe Avon”).

Caracteristicile naționale și culturale tipice britanicilor (adică severitatea și pedantismul britanic) sunt exprimate prin următoarele unități frazeologice cu componentă zooonim:

if wishes were horses, beggars would ride-dacă toate muştele ar face miere, ar fi faguri pe toți pereții (şi la coada calului); 
pigs might fly - când vor zbura porcii;

if the sky falls we'll catch larks - fripți, porumbeii nu zboară în gură; pară mălăiață în gura lui Nătăfleață; nimănui nu-i pică mură-n gură.

În frazeologia engleză pot fi întâlnite şi imagini zoomorfe care denotă exagerări (asupra cuiva), importanța (a ceva sau cuiva), fapte ireale (povești nemaiauzite, legende etc.):

to have the wolf in the stomach/ to be hungry as a wolf - a se hămesi de foamel a avea o foame de lup;

cock and bull story - poveste cusută cu aţă albă „,vorbe ireale spuse cu scopul de a amăgi pe cineva";

shoot (throw) the bull - a îndruga verzi şi uscatel a vorbi ca să treacă timpull a bârfi (argou), a vorbi prostii, a bate câmpii;

no room to swing a cat/ no room to fall - nu e loc nici măcar să te învârtești; enough to make a cat laugh - să râzi de te prăpădești; foarte amuzant;

shaggy-dog story - poveste cu început și fără sfârșit; „,minciună, povestioară sau glumă lungă cu un sfârșit absurd".

Drepturile omului şi caracterul acestuia este reflectat prin intermediul următoarelor frazeologisme: bring your own bears - fă ce dorești; $i$ ' $m$ not afraid, to be a bear for punishment - nu mi-e frică de pedeapsă ,,a nu avea frică de pedeapsă, a merge înainte în ciuda dificultăților”.

Unităţile frazeologice cu componente zoonime pot descrie relația dintre un bărbat și o femeie, evidențiind trăsături privind comportamentul şi aspectul lor fizic. Astfel, bărbatul preocupat de aspectul său fizic, ale cărui atuuri le pune în practică, este descris prin intermediul zoonimelor: horse (armăsar) „bărbat activ”; wolf (lup) „bărbat seducător, afemeiat, cu o viață sexuală activă”; jolly dog (petrecăreț) „afemeiat, cuceritor/ idolul femeilor, tip amuzant/ ciudat/ caraghios/ haios”. Femeia ca mamă şi soție poate fi caracterizată prin intermediul zoonimului tiger (tigroaică) ca o fire feroce (dacă este vorba de o mamă care îşi protejează copiii).

Mai des sunt utilizate zoonimele cu valoare simbolică. Un număr specific de zoonime devin simboluri fiind asociate, în primul rând, cu particularităţile fizice sau trăsăturile de caracter ale unei persoane. Din aceste considerente, zoonimele sunt împărțite în două grupuri. Primul grup include simbolurile referitoare la calitățile pozitive ale persoanei. Deci, în epoca modernă britanicii, referindu-se la o persoană care se caracterizează prin acţiuni rapide şi hotărâte, o pot numi hare (iepure) sau tiger (tigru); iar o persoană puternică şi rezistentă o vor numi ass (măgar), horse (cal), bull (bou) și bear (urs), date fiind trăsăturile fizice ale animalelor desemnate prin zoonimele menţionate. Al doilea grup constă din simboluri asociate cu trăsături de caracter negative. Dacă un englez numește pe cineva bear, atunci acesta face aluzie la tulburarea fizică și/ sau mintală sau la comportamentul grosolan al persoanei date. Numind pe cineva lion (leu), britanicii se referă la imaginea 


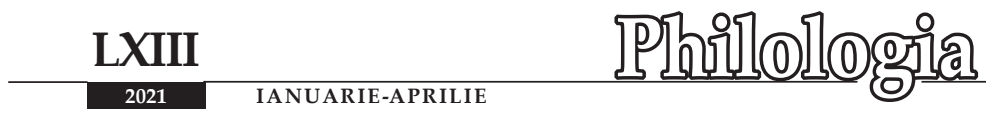

stereotipică corespunzătoare acestui animal, a cărui trăsătura principală de caracter este cruzimea.

În limba engleză, există numeroase zoonime care sunt asociate cu calităţi umane, precum precauţia, care şi-a găsit expresie în unitatea frazeologică cu componenta zoonim let sleeping dog lie - când nenorocirea doarme, fereşte-te s-o deştepţi; lasă-i pe duşmani să doarmă; nu zgândări rănile vechi; nu-i bine să dezgropi morţii; nu deştepta câinele/ leul/ şarpele care doarme. Reprezentarea unei amenințări ascunse este exprimată prin unitățile frazeologice: beware of a silent dog \& still water - ferește-te de câinele tăcut și de apa liniștită; still water runs deep - apa lină sapă adânc.

\section{Concluzii:}

Făcând parte din viaţa şi activitatea omului, animalele influenţează asupra formării concepţiilor estetice ale societăţii. Unităţile frazeologice cu componente zoonime, prin conținutul lor, sunt motivate de unele fenomene extralingvistice bazate pe: concepții pre-științifice despre lume, simboluri culturale, intertextualitate, aspecte ale culturii materiale și aspecte ale interacțiunii social-culturale. Lexemele ce denotă realii, simboluri și etaloane culturale în componența unităților frazeologice cu componente zoonime fac parte din conţinutul semnificației frazeologice și totodată, sunt mijloace de interpretare lingvoculturală. Imaginea aflată la baza frazeologismului poate servi drept indice pentru interpretarea lingvoculturală cu condiția că ea oglindește caracteristicile naționale ale viziunii asupra lumii.

\section{Referințe bibliografice:}

GRANGER, Sylviane, MEUNIER, Fanny. Phraseology: an Interdisciplinary Perspective. Amsterdam: John Benjamins Publishing Company, 2008.

HRISTEA, Theodor. Introducere în studiul frazeologiei. În: Sinteze de limba română. București: Editura Albatros, 1984.

SMITH, Logan, P. Words and Idioms: studies in the English Language. Glasgow: The University Press, 1995.

TELIA, Veronica. Phraseology as a Language of Culture: It's Role in the Representation of a Cultural Mentality. Phraseology. Theory, Analysis, and Applications. Ed. by A.P. Cowie. Oxford: Clarendon Press, 1998.

Kiprijanova = КИПРИЯНОВА, А. А. Функциональные особенности зооморфизмов: на материале фразеологии и паремиологии русского, английского, французского и новогреческого языков. Krasnodar, 2001, 217 с.

Kurajova = КУРАЖОВА, И. В. Имена животных как отражение ценностной картинь мира в английской лингвокультуре. Ivanovo, 2007, 201 с. 